TAXONOMY AND NOMENCLATURE

\title{
A new species of the Xestoblatta surinamensis group from Amazonia, northern Brazil, with redescriptions of $X$. amaparica, $X$. surinamensis and $X$. vera (Blattodea: Ectobiidae)
}

\author{
${\text { Luiz Rafael Silva-da-Silva }{ }^{1} \& \text { Sonia Maria Lopes }}^{1}$
}

\begin{abstract}
'Departamento de Entomologia, Museu Nacional, Universidade Federal do Rio de Janeiro. Quinta da Boa Vista, São Cristóvão, 20940-040 Rio de Janeiro, RJ, Brazil. E-mail: profcien@gmail.com, sonialfraga@gmail.com
\end{abstract}

\begin{abstract}
Xestoblatta Hebard, 1916 is revisited, with description of X. urucuana sp. nov. from northern Brazil. Additionally the hitherto known species X. amaparica Rocha e Silva Albuquerque \& Gurney, 1962, X. surinamensis Bruijning, 1959 and X. vera Rocha e Silva Albuquerque \& Fraga, 1975, are redescribed. Information on the genitalia of the males is also provided. All the species are included in the Xestoblatta surinamensis species group and the placement of X. jygautieri Grandcolas, 1992 in this group discussed. To facilitate species identification, we provide a key to the species of the $X$. surinamensis group, characterized by the subgenital plate with left style (ventral view) about two to five times larger than right style; right paraproct (dorsal view) with three lobes, one with a spiny projection, and median sclerite slender and lanceolate.
\end{abstract}

KEY WORDS. Blattelinae, Dictyoptera, taxonomy.

The members of Xestoblatta Hebard, 1916 are nocturnal cockroaches inhabiting underground shelters and leaf litter in tropical forests (SCHAL et al. 1984). They occur from southern Brazil (Santa Catarina) to Central America, in Panama, Costa Rica and Guatemala (Beccaloni 2016). Hebard (1916) described Xestoblatta in the "Ischnopterites" group, and distinguished this genus from others based on the medium to large size of the body, pronotum wide without sulci, and marginal field of the wing pale yellow. In his diagnosis, Hebard (1916) did not fully describe the genitalia of the specimens, mentioning only characters of the subgenital plate.

GuRnEy (1939) considered Xestoblatta as one of the most diverse groups of Blattodea in the Neotropics, and highlighted the notable morphology of the tergal modifications of the seventh abdominal segment. He described 13 new species and previously unknown males of two other species, and remarked on the importance of the male tergal modifications and genitalia, stressing that these modifications can reveal the evolutionary history of species. GuRNEY (1939) also added notes on the biology and geographic distribution of the species of Xestoblatta, and provided an identification key to species. In his descriptions, special attention was given to the paraprocts. He demonstrated wide interspecific variation in this structure, and also described and illustrated the median sclerite (L2vm) of X. braziliae Gurney, 1939.

Descriptions of Xestoblatta species published after GuRnEy's (1939) contribution, for example Xestoblatta surinamensis Brui- jning, 1959, Xestoblatta amaparica Rocha e Silva Albuquerque \& Gurney, 1962, and Xestoblatta vera Rocha e Silva Albuquerque \& Fraga, 1975, still lack information on the internal genitalia, which is an omission of valuable taxonomic data.

Rотн (1970) demonstrated that the study of the male genitalia helps to avoid ambiguity in the taxonomic placement of many specimens, and that this information is also valuable in the classification of subfamilies, genera and species.

Lopes \& Oliveira (2007), Pellens \& Grandcolas (2008), Lopes et al. (2012), Silva-Da-Silva \& Lopes (2015) and Evangelista et. al. (2015) included Xestoblatta in the subfamily Blattellinae, which is characterized by a hook-shaped phallomere in the male genitalia (L3). This structure, when viewed dorsally, is located on the insect's left side.

The Xestoblatta surinamensis species group was stablished by GrandColas (1992) including the species X. caussaneli Grandcolas, 1992, X. surinamensis and X. amaparica. Here is also included X. vera, X. jygautieri Grandcolas 1992 and X. urucuana sp. nov. We propose to remove $X$. caussaneli from the aforementioned group due the configuration of the narrow subgenital plate, the left phallomere (L3), and particularly the hook-shaped paraprocts, since these characters do not agree with the pattern of the group.

The $X$. surinamensis group is distributed throughout South America, specifically in Suriname, French Guiana, Venezuela and Brazil (Amapá, Amazonas, Mato Grosso and Pará). 
In this contribution, we redescribe $X$. amaparica, $X$. vera, and $X$. surinamensis, and the male genitalia is described for the first time. A new species, X. urucuana sp. nov., is also described.

\section{MATERIAL AND METHODS}

The genital plates were dissected after the posterior part of the abdomen was removed, using traditional techniques as described by LoPEs \& OlIVEIRA (2000). After analysis, the genitalia were stored in microvials with glycerin and attached to the respective specimen, as recommended by GuRNEY et al. (1964). The male abdominal tergal modifications were observed through the base of the wings, after the structures were relaxed with a detergent solution. The terminology for the genitalia and the taxonomic classification follow Rотн (2003). Specimens were determined by comparison with specimens of Xestoblatta deposited in the "Blattaria Collection" of the Museu Nacional, Universidade Federal do Rio de Janeiro, Rio de Janeiro, Brazil (MNRJ), and with descriptions in the literature. Images of the habitus and morphological details were taken with a camera coupled to a stereoscopic microscope. The holotypes of $X$. vera and $X$. urucuana sp. nov., and paratypes of $X$. surinamensis and $X$. amaparica were examined. The location of the holotype of $X$. surinamensis is unknown (BECCALONI 2016). Characters of $X$. caussaneli and $X$. jygautieri were based on illustrations in the original description and on photographs provided by the Muséum National d'Histoire Naturelle, Paris, France.

\section{TAXONOMY}

\section{Xestoblatta surinamensis species group}

Diagnosis. Coloration glossy brown, with two brown marks on laterals of pronotum (ventral view). Subgenital plate with left style (ventral view) about two to five times larger than right style. Right paraproct (dorsal view) with three lobes, one lobe bearing spiny projection. Median sclerite slender, lanceolate.

\section{Xestoblatta urucuana sp. nov.}

Figs. 1-12

urn:Isid:zoobank.org:act:FA6BDF8F-5454-4AB2-88CD-292F0B8BDBC3

Diagnosis. General coloration brown (Fig. 1). Head. Vertex yellowish; palp light brown (Fig. 2). Pronotum glossy brown on lateral margins (Fig. 3). Legs yellowish with dark-brown spines. Coxa with small dark-brown marks along its length. Pulvilli and arolia white. Tegmen with anal field dark brown, lateral flap brownish-yellow. Abdomen brown. Supra-anal and subgenital plates brownish-yellow.

Dimensions (in mm). Total length: 18.4; length of pronotum: 4.6; width of pronotum 4.2; length of tegmen: 15.7; width of tegmen: 7.2.

Description of the male Holotype. Head triangular; interocular space narrow, $0.78 \mathrm{~mm}$, less than half distance between antennal bases; vertex completely exposed. Ocelli small, inconspicuous. Antennae long, slender, exceeding apex of abdomen.
Thorax. Pronotum convex and subtrapezoidal. Disc of pronotum lacking grooves. Fore femur, anteroventral surface with a row of 13 spines gradually decreasing in size apically, and two apical spines; middle femur, anteroventral surface with a row of seven spines gradually decreasing in size apically. Geniculate spine present; posteroventral surface with four spines subequal in size. Hind femur with row of six subequal spines on anteroventral surface, plus apical spine and geniculate spine. Middle and hind coxae bearing lateroapical projections on inner surface. Arolia present. Claws symmetrical and unspecialized. Tegmen developed, exceeding apex of abdomen, wider in anterior third; marginal field well demarcated and slightly concave; scapular field slightly enlarged and round; discoidal field ample, anal field wide, with eight auxiliary veins. Wings developed; ulnar vein with five complete rami; apical triangle not developed; anal field folded in fan.

Abdomen. Median tergal modification on tergite VII shaped as shallow sulcus (Fig. 4). Subgenital plate widened, with lower margin setose, apex curved, slightly projected. Right stylus (ventral view) inserted near median surface, digitiform, weakly sclerotized, small, measuring about $1 / 5$ of left stylus, bearing spiny projection near margin of the plate (Fig. 6); left stylus (ventral view) central, elongated, sclerotized, curved at apex, near margin of subgenital plate (Fig. 5). Supra-anal plate with median sulcus on lower margin (Fig. 7). Left paraproct (Fig. 8) slender, sclerotized, with three slender structures, one of these with two apical spines. Right paraproct digitiform, sclerotized, rounded apically, with three apical spines (Fig. 9). Genitalia with left phallomere (L3) hook-shaped, concave, sclerotized, slender distally (Fig. 10). Median sclerite long (L2vm), slender, apex lanceolate (Fig. 11). Right phallomere (R2) triangular medially, sclerotized, and bearing distally curved sclerotized structure (Fig. 12).

Material examined. Holotype male. BrazIL, Amazonas: Coari municipality (Rio Urucu, ROC 27', 04²9'33"S/06501'49"W, 05,17, 29/09/1995), P.F. Bührnheimer \& N.O. Aguiar leg. (Shannon trap). Paratypes 9 males and 3 females with same data as holotype. All specimens deposited in MNRJ.

Etymology. The specific name refers to the type locality along the Urucu River, state of Amazonas, northern Brazil.

Remarks. Xestoblatta urucuana sp. nov. is similar to $X$. surinamensis in size, shape of paraprocts, tergal modifications on tergite VII, and median sclerite with lanceolate tip; but differs sharply from $X$. surinamensis by the configuration of the subgenital plate widened, with the lower margin setose, apex curved and slightly projected. Right stylus (ventral view) inserted near median surface, digitiform, weakly sclerotized, small, measuring about 1/5 of left stylus, bearing spiny projection near margin of plate (Fig. 5).

\section{Xestoblatta amaparica}

\section{Rocha e Silva Albuquerque \& Gurney, 1962}

Figs. 13-23

Diagnosis. General coloration pale brown (Fig. 13). Head opaque with dark-brown marks scattered over it (Fig. 14). Vertex 


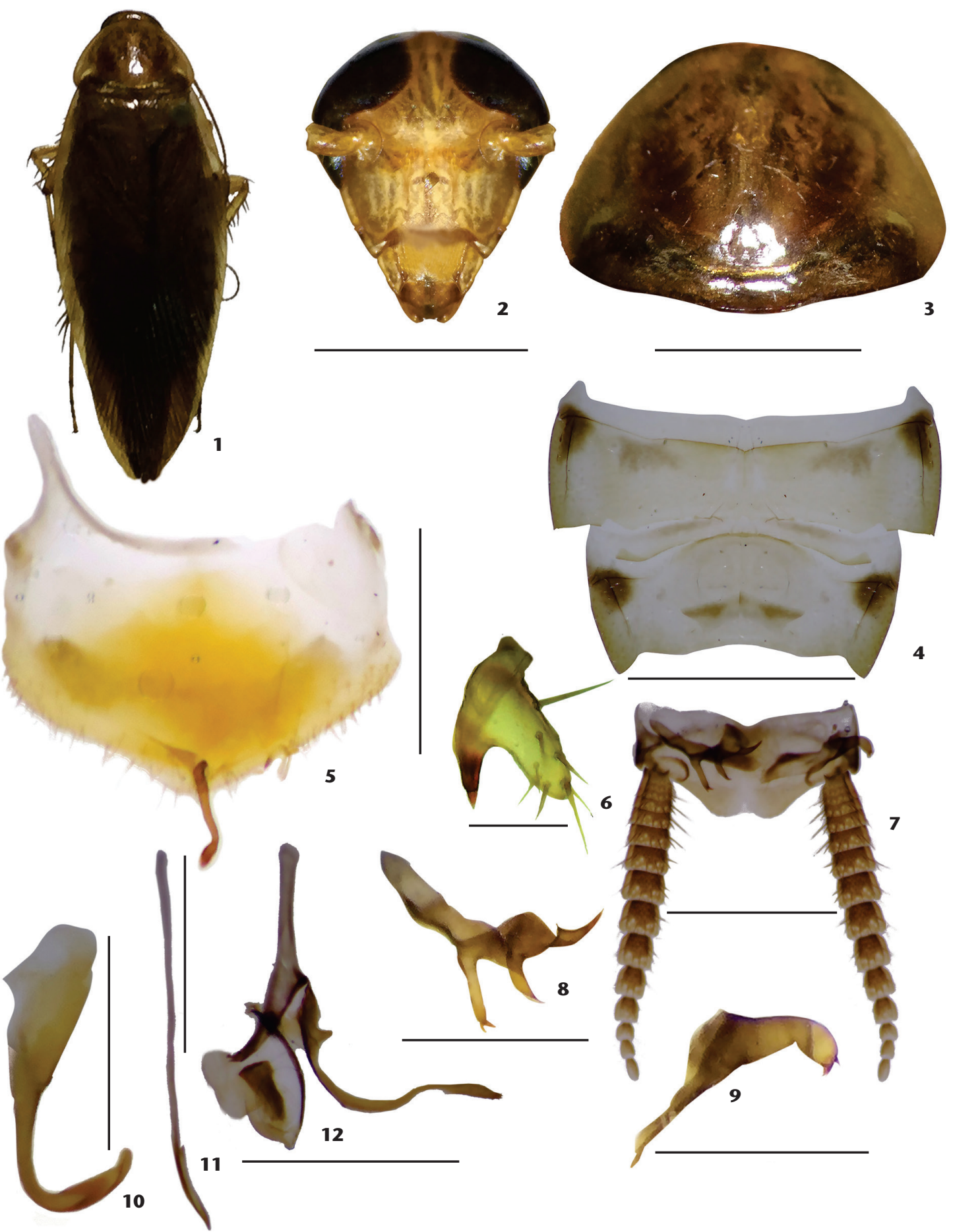

Figures 1-12. Xestoblatta urucuana sp. nov., holotype male: (1) habitus, dorsal view, length $18.4 \mathrm{~mm}$; (2) head, ventral view; (3) pronotum, dorsal view; (4) tergal modification of the tergite VII, dorsal view; (5) subgenital plate, ventral view; (6) left style, ventral view; (7) supra anal plate, dorsal view; (8) left paraproct, dorsal view; (9) right paraproct, dorsal view; (10) left phallomere (L3), dorsal view; (11) median esclerite (L2vm), dorsal view; (12) right phallomere (R2), dorsal view. Scale bars: $2=2.5 \mathrm{~mm}, 3-4=3.0 \mathrm{~mm}, 5,11-12=1.5 \mathrm{~mm}$, $6=0.15 \mathrm{~mm}, 7=1.8 \mathrm{~mm}, 8-9=0.8 \mathrm{~mm}, 10=0.7 \mathrm{~mm}$. 


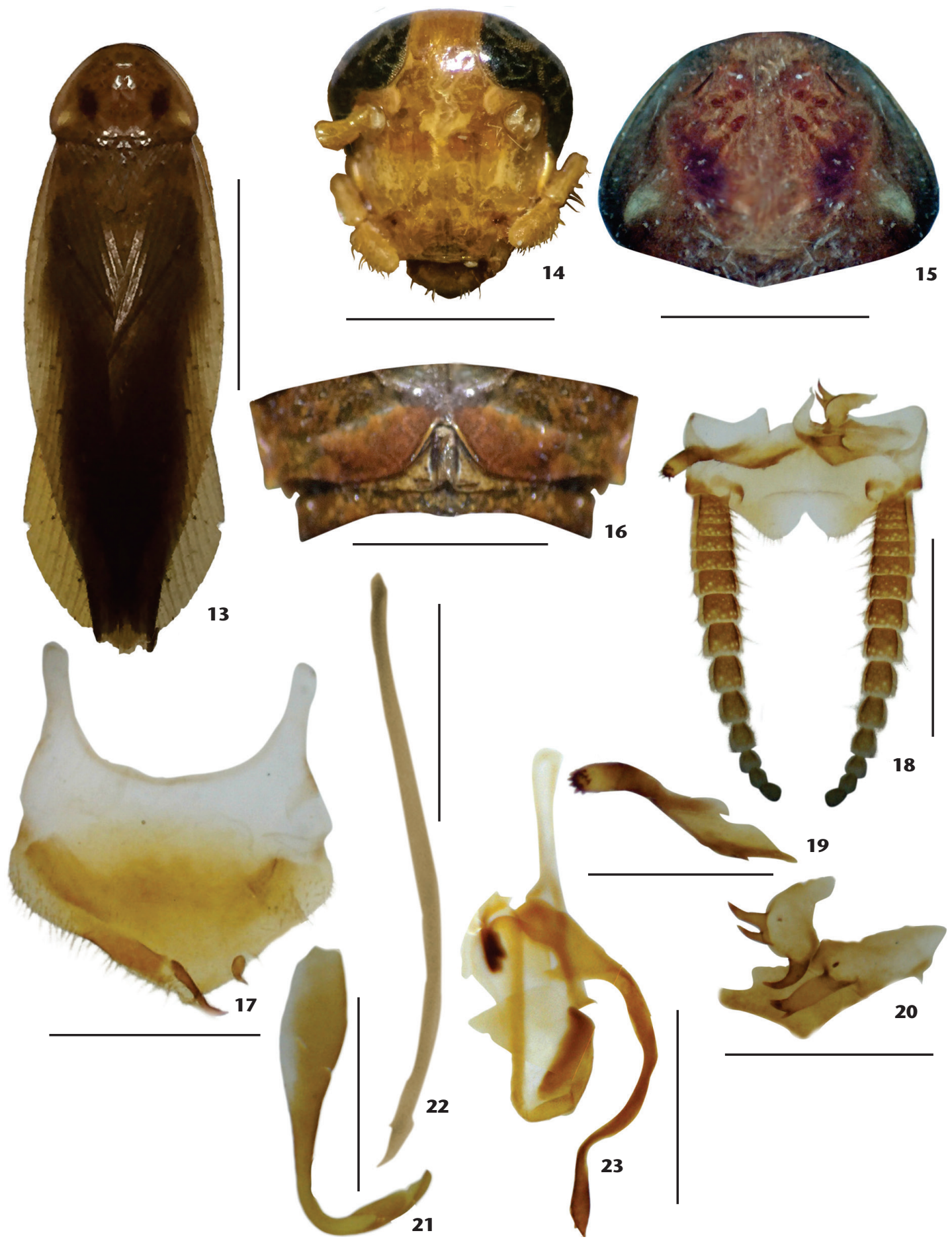

Figures 13-23. Xestoblatta amaparica, paratype male: (13) Habitus, dorsal view, length $23 \mathrm{~mm}$; (14) head, ventral view; (15) Pronotum, dorsal view; (16) Tergal modification of the tergite VII, dorsal view; (17) Subgenital plate, ventral view; (18) Supra anal plate, dorsal view; (19) Left paraproct, dorsal view; (20) Right paraproct, dorsal view; (21) Left phallomere (L3), dorsal view; (22) median sclerite (L2vm), dorsal view; (23) Right phallomere (R2), dorsal view. Scale bars: 14, $16=2.5 \mathrm{~mm}, 15=3.0 \mathrm{~mm}, 17-18=2.0 \mathrm{~mm}, 19-20,22-23=1.0$ $\mathrm{mm}, 21=0.7 \mathrm{~mm}$. 
with small brown mark, interocular space with ill-defined dull bands, paler anteriorly, separated from clear area. Maxillary palp brownish yellow. Ocelli brown. Pronotum brown, margin narrow and dull. Central disk opaque with dark marks on each side of median area (Fig. 15). Legs pale, with marks. Color of spines same as legs. Legs. tegmen translucent brown.

Dimensions (in mm). Total length: 22-23; length of pronotum: 4.00; width of pronotum: 4.87; length of tegmen: 16.83; width of tegmen: 7.41 .

Redescription. Head triangular, with ocelli developed, interocular space $0.64 \mathrm{~mm}$, almost half distance between antennal bases. Vertex slightly exposed. Pronotum convex and subtrapezoidal, apex straight, base slightly angular with lateral flaps slightly deflexed and margins round, widest at mid-caudal region. Disk of pronotum without sulci. Legs long, robust, with wide coxae. Femur I with anteroventral margin bearing row of 13 long spines gradually decreasingin size apically, ending in three long spines. Femora II and III with 7 spines on both surfaces; with geniculate spine. Pulvilli, arolia and claws moderately developed. Tegmen well-developed, marginal field slightly deflected, median vein with three rami, 6 cubital and 7 anal veins. Abdomen with tergite VII bearing tergal modification, with deep depression divided medially by conspicuous prominence (Fig. 16). Sixth tergite emarginate posteriorly. Supra-anal plate triangular, ample, projected between cerci and with bilobed apex (Fig. 18). Right paraproct cylindrical, with apex bulbous and a few apical spines (Fig. 19). Left paraproct with two lobes, one trifid, the other cylindrical with three apical spines (Fig. 20). Subgenital plate small, asymmetric (Fig. 17). Right stylus (ventral view) small, sclerotized, curved medially; left stylus elongate, sclerotized, curved apically. Left phallomere hook-shaped (L3), with apex slightly dilated, and small globular apical projection (Fig. 21). Median sclerite slender (L2vm), simple (Fig. 22). Right phallomere (R2) with elongated projection, widened distally, bearing spines (Fig. 23).

Material Examined. Paratypes 3 males, 2 females. BRAzIL, Pará: I.P.A.M. [Instituto de Pesquisa Ambiental da Amazônia], 04/1966, L. Gomes leg. All specimens deposited in MNRJ.

Remarks. The subgenital plate of $X$. amaparica is consistent with the pattern found in the $X$. surinamensis group with respect to size, insertion of styles, and shape of paraprocts. It differs from other species of the group in the configuration of the styles on the subgenital plate (Fig. 17), and the right paraproct cylindrical with a bulbous apex and a few apical spines (Fig. 19).

\section{Xestoblatta surinamensis Bruijning, 1959}

Figs. 24-34

Diagnosis. General coloration brownish (Fig. 24). Head ferruginous yellow (Fig. 25), stained yellowish-brown between antennal insertions; vertex and interocular space same color as head. Clypeus with two small marks on lateral margins, labrum dark brown. Ocelli pale brown, inconspicuous. Pronotum brownish-yellow with small dark-brown marks on lateral margin; central disk yellowish-brown, inconspicuous (Fig. 26).
Legs ferruginous yellow, coxae with two small pale brown marks. Spines ferruginous yellow, pulvilli white, arolia ferruginous yellow. Tegmen stained yellowish brown, except marginal field paler. Tergite and sternite following general coloration of body. Sternite with small lateral pale-brown marks.

Dimensions (in mm). Total length: 22.8; length of pronotum: 4.5 ; width of pronotum: 6.4 ; length of tegmen: 17.3 ; width of tegmen: 4.3 .

Redescription. Head oval-triangular, interocular space narrow, $0.82 \mathrm{~mm}$, slightly less than half distance between antennal bases. Ocelli small and inconspicuous. Vertex slightly exposed. Maxillary palp setose on all segments.

Thorax. Pronotum slightly convex, very slight angulation on posterior margin, maximum width in medio-basal region. Lateral flaps short, not deflexed. Legs robust with wide coxae; femur I with anteroventral surface bearing row of 12 long spines gradually decreasing in size apically, and ending in three long apical spines. Posteroventral surface with five equally spaced spines, the last spine apical. Pulvilli and arolia well developed, claws moderately developed. Tegmen well developed, exceeding apex of cerci. Marginal field slightly deflected, narrow. Discoidal field rounded. Scapular field ample. Anal field straight.

Abdomen. First to fourth tergites bearing angular lateral humps, sixth tergite with conspicuous lateromedially humps. Apical margin of fifth tergite twice emarginated laterally. Sixth tergite with large median depression. Seventh segment retracted (Fig. 27) and rounded, bearing marginal cilia (Fig. 28). Left style (ventral view) cylindrical, unsclerotized, concave at apex, slightly larger than right styles, conical, unsclerotized. Supra-anal plate triangular, projected between cerci, bilobed distally, with median notch (Fig. 29). Right paraproct with slender bifid sclerotized structure, and third structure round, with three sclerotized apical spines (Fig. 30). Left paraproct single, rhomboid, with rounded apex and three small sclerotized spines (Fig. 31). Left phallomere hook-shaped (L3), apex slightly dilated and curved (Fig. 32). Median sclerite (L2vm) sword-shaped (Fig. 33). Right phallomere (R2) bearing inverted V-shaped structure with spiny projection (Fig. 34).

Material examined. Paratype 1 male. Brazil, Pará: Castanhal municipality, 1964, Pirelli \& M. Monné leg. (MNRJ).

Remarks. Xestoblatta surinamensis is similar to X. vera in the shape of the subgenital plate, insertion of styles, and paraprocts. They differ in the pattern of the projection of the right phallomere and in the sword-shaped configuration of the median sclerites.

\section{Xestoblatta vera}

\section{Rocha e Silva Albuquerque \& Fraga, 1975 Figs. 35-47}

Diagnosis. General coloration yellowish-brown (Fig. 35). Head pale yellow; vertex yellowish, interocular space slightly pigmented, frons with transverse dark-brown mark linking antennal insertions between antennae; clypeus with dark marks, labrum dark brown (Fig. 36). Pronotum glossy brown, with two 


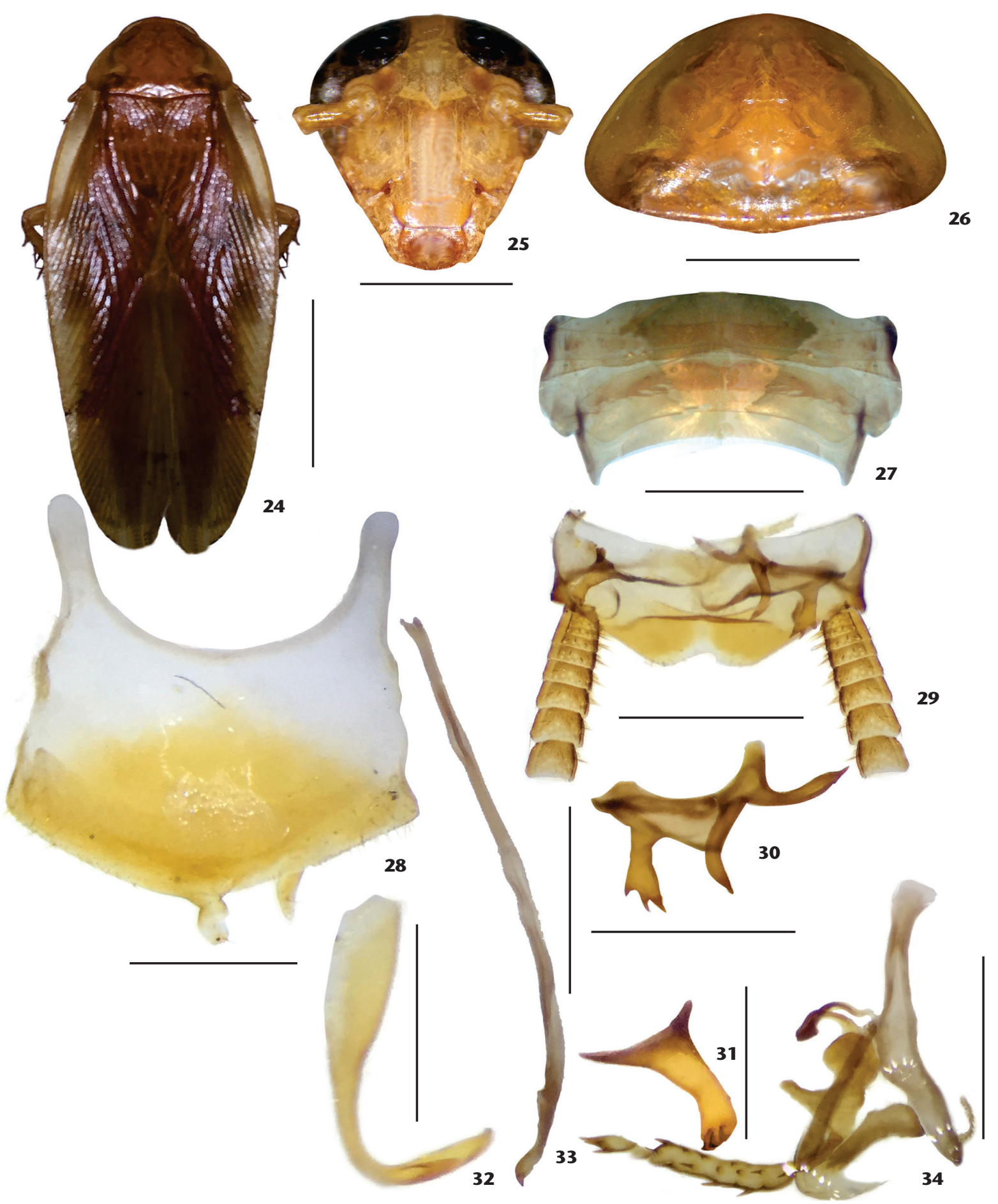

Figures 24-34. Xestoblatta surinamensis, paratype male: (24) habitus, dorsal view, length $22.8 \mathrm{~mm}$; (25) head, ventral view; (26) pronotum, dorsal view; (27) tergal modification of the tergite VII, dorsal view; (28) subgenital plate, ventral view; (29) supra anal plate, dorsal view; (30) left paraproct, dorsal view; (31) right paraproct, dorsal view; (32) left phallomere (L3), dorsal view; (33) median sclerite (L2vm), dorsal view; (34) right phallomere (R2), dorsal view. Scale bars: $25=7.0 \mathrm{~mm}, 26=2.0 \mathrm{~mm}, 27=3.0 \mathrm{~mm}, 28=1.2 \mathrm{~mm}, 29=1.7 \mathrm{~mm}$, $30,33=1.0 \mathrm{~mm}, 31=0.6 \mathrm{~mm}, 32=0.8 \mathrm{~mm}, 34=1.5 \mathrm{~mm}$. 


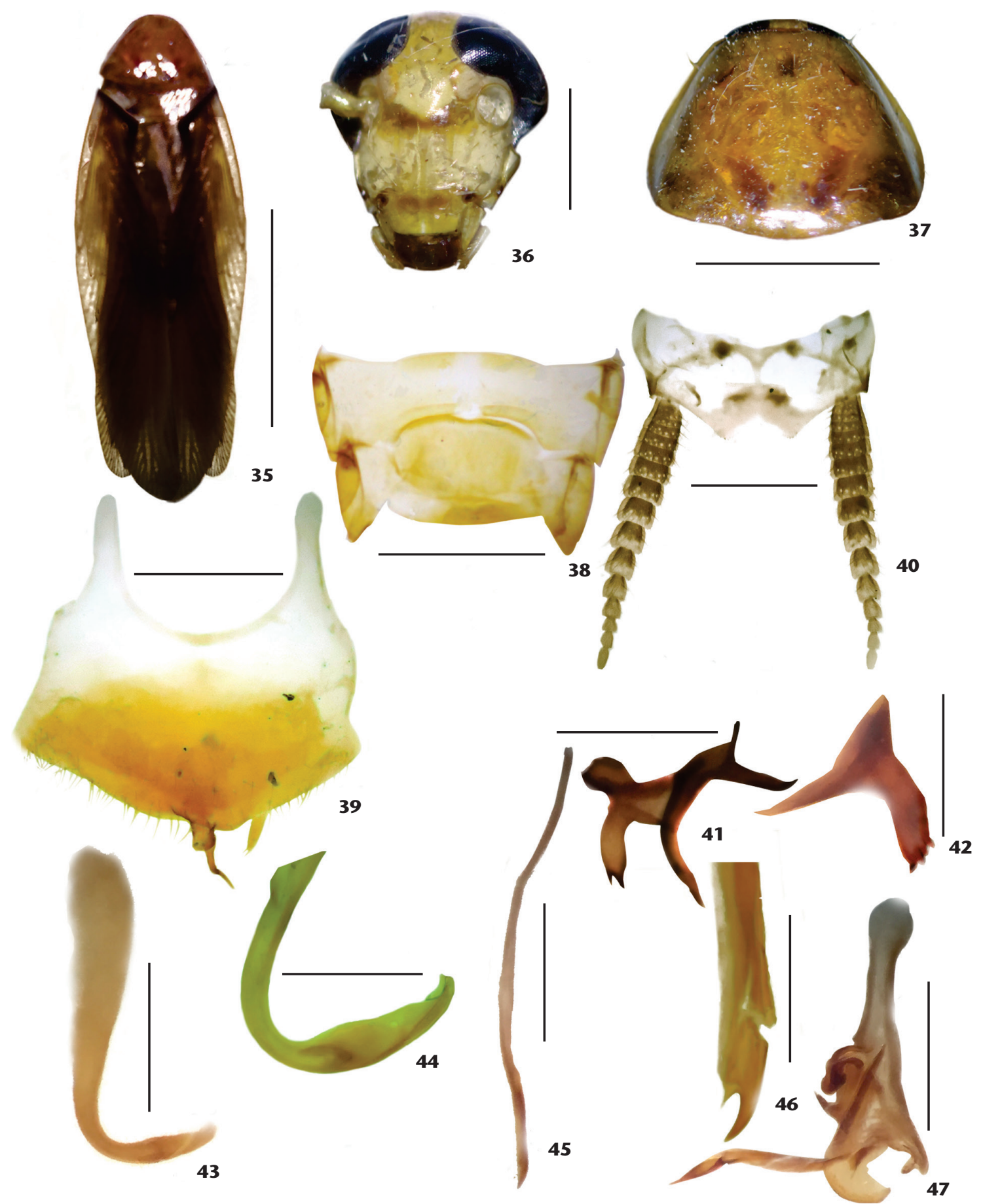

Figures 35-47. Xestoblatta vera, paratype male: (35) habitus, dorsal view, length $22.4 \mathrm{~mm}$; (36) head, ventral view; (37) Pronotum, dorsal view; (38) Tergal modification of the tergite VII, dorsal view; (39) Subgenital plate, ventral view; (40) Supra anal plate, dorsal view; (41) Left paraproct, dorsal view; (42) Right paraproct, dorsal view; (43) Left phallomere (L3), dorsal view; (44) Apex of left phallomere, dorsal view; (45) median esclerite (L2vm), dorsal view; (46) Apex of mediam sclerite, Scale Bar:0,4mm; (47) Right phallomere (R2), dorsal view. Scale bars: $36=1.5 \mathrm{~mm}, 37=3.5 \mathrm{~mm}, 38=3.0,39=1.3 \mathrm{~mm}, 40=1.5 \mathrm{~mm}, 41,45,47=1.0 \mathrm{~mm}, 42=0.5 \mathrm{~mm}, 43=0.5 \mathrm{~mm}, 44=$ $0.3 \mathrm{~mm}, 46=0.4 \mathrm{~mm}$. 
symmetrical black marks on medio-basal region and two small narrow dark-brown marks in medio-apical region; central disk inconspicuous (Fig. 37). Antennae brown, basal segments paler, similar to head coloration. Maxillary palp yellowish. Ocelli whitish. Legs yellowish, apex of coxae brown; spines brown, pulvilli white, arolia brown. Tegmen brownish-yellow and glossy, with hyaline marginal field. Tergite yellowish-brown, sternite yellowish-brown with marks on segments I-VII.

Dimensions (in $\mathrm{mm}$ ). Total length: 22.4 ; length of pronotum: 4.2 ; width of pronotum: 5.4; length of tegmen: 18.6; width of tegmen: 4.3 .

Redescription. Head oval-triangular, interocular space narrow, $0.5 \mathrm{~mm}$, slightly less than half distance between antennal bases. Ocelli small and inconspicuous. Vertex slightly exposed.

Thorax. Pronotum slightly convex, with slight angulation on posterior margin, maximum width in medio-basal region, with deflexed lateral flaps. Legs robust and densely spiny with large coxae; femur I with anteroventral surface bearing row of 13 long spines gradually decreasing in size apically, and ending in three long apical spines. Posteroventral surface with five equally spaced spines, the last apical. Pulvilli, arolia and claws moderately developed. Tegmen well-developed, well exceeding apex of cerci. Marginal field slightly deflexed, narrow. Discoidal field rounded. Scapular field ample. Anal field straight. Subcostal vein long and sinuous, about 20 radial sectors, with apical sector ramified. Wing with three complete rami on cubital vein; apical triangle small but conspicuous. Four complete auxiliary veins.

Abdomen. Tergal modification on tergite VII shaped as wide central depression, slightly rounded, partially covered by anterior tergite (Fig. 38). Subgenital plate asymmetrical, ciliated marginally, with styles differentiated in size, inserted mediodistally; margin of subgenital plate setose. Left style (ventral view) lobulate with long slender apical projection; right stylus (ventral view) simple, conical, with long setae (Fig. 39). Supra-anal plate triangular, projected between cerci, with median notch between cerci bearing 15 segments (Fig. 40). Right paraproct with slender bifid sclerotized structure and with a third curved structure bearing two sclerotized spines at apex (Fig. 41). Left paraproct single, rhomboid, with apex curved and bearing four small sclerotized spines (Fig. 42). Left phallomere sclerotized (L3), hook-shaped with apical concavity (Figs. 43-44). Median sclerite (L2vm) slender with spiny projection distally; apex slightly sclerotized and apical-lateral projection lobulate (Figs. 45-46). Right phallomere (R3) slightly sclerotized, with slender projection ending in two sclerotized spines (Fig. 47).

Material examined. Holotype male. BraziL, Mato Grosso: Vera municipality, 1973, Alvarenga \& Roppa leg. (MNRJ).

Remarks. Rocha e Silva-Albuquerque \& Fraga (1975) considered this species to be similar to X. ecuadorana Gurney, 1939 in the shape of the subgenital plate. However, our observations indicate that it is similar to X. surinamensis in the shape of the subgenital plate and paraprocts with four small sclerotized spines.

\section{Key for males of the Xestoblatta surinamensis group}

1. Subgenital plate with widened, unsclerotized styles in ventral view; right phallomere in dorsal view with marginal spines around the apex. X. surinamensis Bruijning, 1959

1 '. Subgenital plate with left style slender throughout or only apically in ventral view; right phallomere, in dorsal view, lacking spines on apical third.....

...2

2. Only one style sclerotized, with 2-4 apical spines; left paraproct with two lobes, no lobes with distal spines......................... 3

2 '. Both styles sclerotized; left paraproct with two lobes, one lobe with three long distal spines.

X. amaparica Rocha e Silva Albuquerque \& Gurney, 1962

3. Left style long, slender, sclerotized, attached directly to the border of the subgenital plate. Right style short, cylindrical, thin X. urucuana sp. nov.

3'. Left style long, unsclerotized, curved over border of subgenital plate. Right style membranous, rounded ........................... 4

4. Right style short, conical, with one lobe. Median sclerite with projection on the apex .................................................... vera Rocha e Silva Albuquerque \& Fraga, 1975

$4^{\prime}$. Right style short, with two short lobes. Median sclerite lacking projections X. jygautieri Grandcolas, 1992

\section{LITERATURE CITED}

Beccaloni GW (2016) Cockroach Species File Online. Version 5.0/5.0. Available online at: http://Cockroach.SpeciesFile.org [Accessed: 21/01/2016]

Evangelista DA, Chan K, Kaplan KL, Wilson MM, Ware JL (2015) The Blattodea ss (Insecta, Dictyoptera) of the Guiana Shield. ZooKeys 475: 37-87. doi: 10.3897/zookeys.475.7877

Grandcolas P (1992) Évolution du mode de vie, répartition et nouveaux taxons dans le genre Xestoblatta Hebard, 1916 [Dictyoptera, Blattellidae, Blattellinae]. Revue Française d'Entomologie (Nouvelle Serie) 14: 155-168.

GuRney AB (1939) A revision of the neotropical genus Xestoblatta Hebard (Orthoptera; Blattidae; Pseudomopinae). Proceedings of the Entomological Society of Washington 41: 97-128.

Gurney AB, Kramer JP, Steyskal GC (1964) Some techniques for the preparation, study, and storage in microvials of insect genitalia. Annals of the Entomological Society of America 57: 240-242. doi: 10.1093/aesa/57.2.240

Hebard M (1916) Studies in the Group Ischnopterites (Orthoptera, Blattidae, Pseuomopinae). Transactions of the American Entomological Society 42: 337-383.

LOPEs SM, Oliveira EH DE (2000) Espécie nova de Eublablerus Hebard, 1919 do Estado de Goiás, Brasil e notas sobre E. marajoara Rocha e Silva-Albuquerque, 1972 (Blaberidae, Blaberinae). Boletim do Museu Nacional, Zoologia Nova Série, 433: 1-5. 
Lopes SM, Oliveira EH de (2007) Espécie nova de Xestoblatta (Blattaria, Blattellidae) do Estado de Santa Catarina, Brasil. Iheringia, Série Zoologia, 97: 376-378.

Lopes SM, Oliveira EH DE, AssumpÇão M (2012) Two New Species of Ectobiidae (Blattaria) Collected in the Santa Lúcia Biological Reserve, Espírito Santo, Brazil. Neotropical Entomology 41: 468-471. doi: 10.1007/s13744-012-0068-2

Pellens R, Grandcolas P (2008) Catalogue of Blattaria (Insecta) from Brazil. Zootaxa 1709: 1-109.

Rocha e Silva-Albuquerque I, Fraga CRC (1975) Estudo sobre o gênero Xestoblatta Hebard, 1916 (Blattariae): Descrição de três espécies novas da Amazônia. Boletim do Museu Paraense Emílio Goeldi 79: 1-15.

Rотн LM (1970) The male genitalia of Blattaria IV. Blaberidae: Blaberinae. Psyche 77: 217-236. doi: 10.1155/1970/14743

Rотн LM (2003) Systematics and phylogeny of cockroaches (Dictyoptera: Blattaria). Oriental Insects 37: 1-186.

Schal C, Galtier J-Y, Bell WJ (1984) Behavioural Ecology of Cockroaches. Biological Reviews 59: 209-254.
Silva Da Silva LR, Lopes SM (2015) Two new species of Xestoblatta Hebard, 1916 from Brazil, a redescription of Xestoblatta roppai Rocha e Silva Albuquerque \& Fraga, 1975 and a key for the species of the buscki group (Blattodea, Ectobiidae, Blattellinae). Zookeys 12: 117-29. doi: 10.3897/zookeys.545.6172

Submitted: 2 March 2016

Received in revised form: 14 September 2016

Accepted: 2 October 2016

Editorial responsibility: Ângelo Parise Pinto

Author contributions: LRSS and SML participated equally in the preparation of this article.

Competing interests: The authors have declared that no competing interests exist. 